even after multiple chemotherapy lines, platinum sensitivity is associate with a longer therapy-free interval. The aim of this study was to investigate platinum resistance in long-term OvCa survivors.

Methodology Patients diagnosed with OvCa at the Tuebingen University Women's Hospital between 2000 and 2012 were retrospectively identified and follow-up data was collected. For patients surviving at least 8 years a detailed chart review was performed. Platinum resistance was defined as disease progression during platinum-based chemotherapy or 6 months after the last platinum dose administration.

Result(s)* From a total $\mathrm{n}=745$ of patients with adequate follow-up data, $\mathrm{n}=223(30 \%)$ survived at least 8 years after primary diagnosis. Median follow-up was 12.1 years and median age at diagnosis was 54.7 years. Relapse was recorded in 87/ $223(39 \%)$ patients, of which $28 / 87(32 \%)$ developed platinum resistance at some point. Platinum resistance was observed after the second line chemotherapy in most patients (median: 2, range: 1-4). 23/28 patients received further chemotherapy lines (median: 2, range: 0-8). Rechallenge with a platinumbased chemotherapy has been used in 9/28(32\%) patients. Median overall survival of these 28 patients was 9.3 years (8.2-18.4, IQR3.7) and 4.1 (0.4-16.8, IQR3.8) years after platinum resistance.

Conclusion* We were able to demonstrate long-term survival after platinum resistance in a substantial number of ovarian carcinoma patients. Suggesting therefore, that other parameters influence the disease behaviour. Further research of patient characteristics, environmental and genetic features and treatment modalities will help to further understand factors contributing to long-term survival.

\section{PLASMAJET GIVES LESS TISSUE DAMAGE THAN ELECTROCOAGULATION DEVICE DURING CYTOREDUCTIVE SURGERY FOR ADVANCED-STAGE OVARIAN CANCER}

${ }^{1,2} \mathrm{G}$ Nieuwenhuyzen-de Boer*, ${ }^{1} \mathrm{~N}$ Van de Berg, ${ }^{1} \mathrm{XS}$ Gao, ${ }^{3} \mathrm{PC}$ Ewing-Graham, ${ }^{1} \mathrm{HJ}$ Van Beekhuizen. 'Erasmus University Medical Center, Gynaecologic Oncology, Rotterdam, Netherlands; ${ }^{2}$ Albert Schweitzer Hospital, Gynaecology, Dordrecht, Netherlands; ${ }^{3}$ Erasmus University Medical Center, Pathology, Rotterdam, Netherlands

\subsection{6/ijgc-2021-ESG0.354}

Introduction/Background* The aim of surgery for advancedstage ovarian cancer is complete cytoreductive surgery, because this is the most important independent prognostic factor for prolonged survival. Yet this can be difficult to achieve when there are micrometastases on the mesenterium or intestines. The PlasmaJet ${ }^{\circledast}$ Surgical device is an instrument to remove these micrometastases, but little is known about the depth of tissue damage compared to electrocoagulation devices.

Methodology A prospective study was performed to determine the histological depth of thermal damage in tissues in a series of 106 histological slides of 17 advanced-stage ovarian cancer patients to compare thermal damage depth after use of the PlasmaJet ${ }^{\circledast}$ Surgical device with electrocoagulation devices. Depending on which tissue types were resected during complete cytoreductive surgery, samples were collected from reproductive organs (uterus, ovaries), intestines (ileum, colon, rectum) and omentum, mesenterium and peritoneum. A systematic review of the literature on tissue damage with the PlasmaJet ${ }^{\circledast}$ Surgical device was carried out.

Result(s)* Average thermal damage depth was $0.15 \mathrm{~mm}$ (range $0.03-0.60 \mathrm{~mm}$ ) after use of the PlasmaJet and $0.33 \mathrm{~mm}$ (range $0.08-1.80 \mathrm{~mm})$ after use of electrocoagulation $(\mathrm{P}<0.001)$. Greater disruption of the tissue surface was often observed after electrocoagulation use. These results correspond with the available literature.

Conclusion* Based on our case series and review of literature, we conclude that PlasmaJet treatment produces significantly less thermal damage than electrocoagulation treatment. It is therefore considered a safe alternative, aiding in the achievement of complete cytoreductive surgery in patients with advanced-stage ovarian cancer without complications due to perforation of hollow organs.

\section{PERIOPERATIVE DYNAMIC EVALUATION OF FOLATE RECEPTOR ALPHA EXPRESSION IN OVARIAN CARCINOMA}

${ }^{1,2}$ MP Kubelac* ${ }^{1,2} \mathrm{C}$ Vlad, ${ }^{1,2} \mathrm{~B}$ Pop, ${ }^{1} \mathrm{~B}$ Fetica, ${ }^{1} \mathrm{E}$ Fischer-Fodor, ${ }^{1} \mathrm{O}$ Soritau, ${ }^{1} \mathrm{O}$ Balacescu, ${ }^{1,2} \mathrm{~F}$ Ignat, ${ }^{1,2} \mathrm{G}$ Lazar, ${ }^{1,2} \mathrm{C}$ Lisencu, ${ }^{1,2} \mathrm{~A}$ Rancea, ${ }^{1,2} \mathrm{~A}$ Irimie, ${ }^{1,2} \mathrm{P}$ Achimas-Cadariu. ${ }^{1}$ The Oncology Institute "Prof. Dr. Ion Chiricuță" Cluj-Napoca, Cluj-Napoca, Romania; ${ }^{2}$ luliu Hațieganu University of Medicine and Pharmacy, Cluj-Napoca, Romania

\subsection{6/ijgc-2021-ESGO.355}

Introduction/Background* The human folate receptor $\alpha$ (FOLR1) is overexpressed in ovarian cancer and has been correlated with the transformed phenotype in ovarian cancer, platinum sensitivity, and tumor growth. The highly restricted
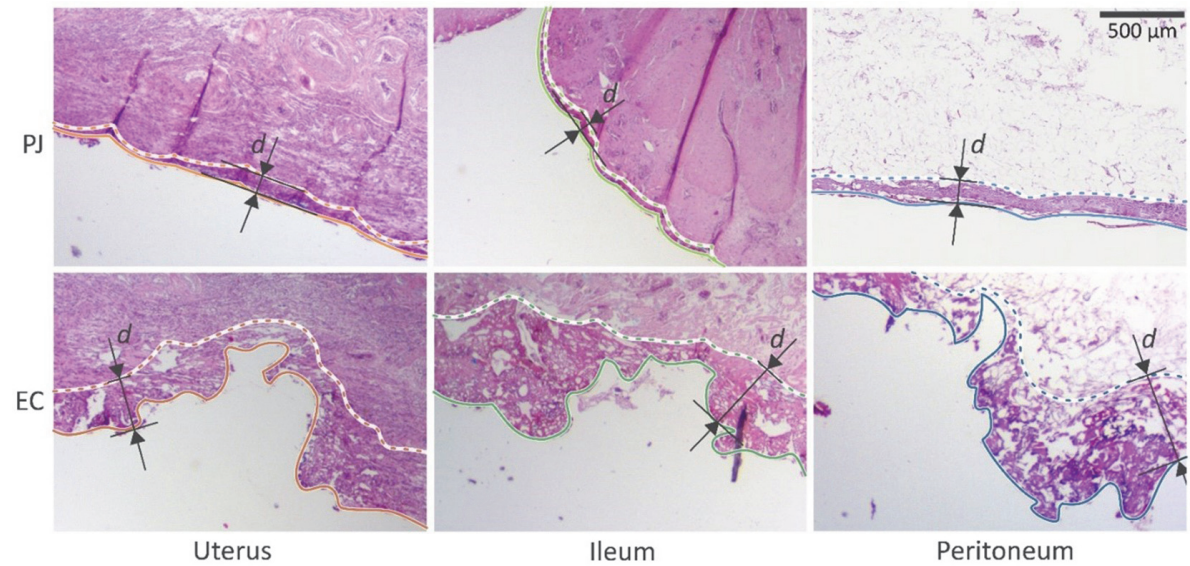